\title{
Aleksander Duda*, Tomasz Siwowski \\ Experimental study on earth pressure reduction of waste tyre bales used as a backfill for rigid retaining structures
}

https://doi.org/10.2478/sgem-2021-0023

received March 30, 2021; accepted August 31, 2021.

\begin{abstract}
Waste tyre-derived products, including whole tyres, tyre bales, shreds, chips and crumb rubber, have been widely used in geotechnical applications. In particular, tyre bales have considerable potential for use in the construction of a lightweight embankment or road foundation over soft ground, slope stabilisation or landslide repairs and the backfilling for retaining structures. Proper design of tyre bale structures requires a reliable strength analysis to ensure an adequate factor of safety. The analysis should utilise the properties of the tyre bales and the baled structures, which must be properly determined. A laboratory test programme was developed to determine the key strength parameters of a backfill made of tyre bales supplemented with a lightweight aggregate. Full-scale direct shear tests were conducted to define the interface shear strength between the tyre bales and the filling material. Earth pressure reduction analysis based on the experimental results was performed as well to assess the effectiveness of waste tyre bales used as a backfill for rigid retaining structures.
\end{abstract}

Keywords: waste tyres; tyre bales; shear strength; earth pressure; retaining structure.

\section{Introduction}

Waste tyre-derived products (TDP), including whole tyres, tyre bales, shreds, chips and crumb rubber, have been widely used in geotechnical applications. The

\footnotetext{
*Corresponding author: Aleksander Duda, Department of Roads and Bridges, Rzeszow University of Technology, Poland, E-mail: a.duda@prz.edu.pl

Tomasz Siwowski, Department of Roads and Bridges, Rzeszow University of Technology, Poland
}

majority of these applications has addressed tyre-derived aggregate (TDA) for use in highway works (Humphrey \& Blumenthal [12], Mills \& McGinn [17], Meles et al. [16], Ahn et al. [1]). However, there are many applications in civil and geotechnical engineering as well (Mittal \& Gill [18], Ni et al. [18], Esmaeili et al. [8], Sol-Sánchez et al. [24]; Xiao et al. [28]). An alternative is the baling of whole waste tyres to produce cuboidal, lightweight, permeable bales. Typical waste tyre bales comprise 100-115 car tyres compressed into a block and secured by galvanised steel tie wires running around the length and depth of the bale. Waste tyre bales have considerable potential for use in geotechnical applications, particularly where their low density, permeability and ease of handling give them an advantage. The use of lightweight bales in the construction of a lightweight embankment or road foundation over soft ground, the backfilling for retaining structures, and slope stabilisation or landslide repairs has the potential to satisfy the demand for low-cost materials exhibiting such a beneficial property (Zornberg et al. [29], Winter et al. [26], Bo \& Yarde [4], Simm et al. [24], Winter et al. [27], Duda \& Siwowski [5]). Proper design of tyre bale structures requires a reliable strength analysis to ensure an adequate factor of safety. The analysis should utilise the properties of the tyre bales and the baled structures, which must be properly determined. To date, the authors know only a few US researches that have been carried out to determine the mechanical properties of the tyre bales. The first research works were conducted at the University of Texas at Austin. La Rocque [14] followed by Zornberg and La Rocque [31] summarise the results of research works conducted to determine the mechanical properties of tyre bales for use in stability analyses, such as unit weight, stiffness, interface shear strength, expansive pressure and timedependent deformations under sustained load. Following these works, the next report (Zornberg et al. [30]) includes the results of laboratory tests on tyre bales to provide the required information on bale geometry, both air dry and submerged unit weights, permeability, unconfined and 
confined compressibility characteristics, creep behaviour and shear strength between two tyre bales. Again, at the University of Texas, a laboratory testing programme was conducted to determine the compressibility properties of the bales required for design (Freilich \& Zornberg [9]). Finally, Winter et al. [26] carried out an extensive study on key tyre bales' geometrical, mechanical and hydraulic properties, revealing the current needs for further research: high-quality mechanical tests, including stiffness, shear strength and creep.

One of the potential applications of waste tyre bales is their use as a backfill for rigid retaining structures and bridge abutments (typically made of concrete). The lightweight backfill consisting of waste tyre bales, additionally supplemented with lightweight aggregate, considerably reduces the earth pressure on the retaining wall, allowing for a more economical construction by designing a lighter (thinner) wall with less reinforcing. Additional structural profit can be obtained when the application of the tyre baled backfill for integral bridges is considered. In integral bridges, daily and seasonal thermal movements of the superstructure cause interactions between the bridge abutment and retained backfill. There is a greater risk of high passive pressures developing at the backwall of the abutment, leading to possible structural damages. One of the means of avoiding this high pressure on an integral abutment is to use a compressible, elastic, amortising (stress-absorbing) material providing low passive pressure, which is much lower than in the case of a conventional granular backfill. Tyre bales can act as such a compressible filling material. The pressure acting on integral abutment by tyre bales can potentially be as low as those on non-integral abutments, significantly reducing the cost of an abutment. Furthermore, a retaining wall (or abutment) will normally have a drainage layer behind the backwall to minimise the hydrostatic forces acting on the wall and the permeable bales will form a good drainage path. However, no known application of the waste tyre bales in retaining wall / bridge abutment backfill has been reported to date, although the concept has been widely discussed (Winter et al. [26], Zornberg et al. [30]). No experimental or numerical studies on earth pressure reduction of waste tyre bales used as a backfill for rigid retaining structures have been conducted to determine the mechanical parameters of tyre baled backfill for design purposes. Therefore, tests are required to enable wider use of tyre bales in these particular applications. A domestic laboratory testing programme was prepared to determine the basic mechanical properties required for the design of retaining structures with tyre bales. The laboratory full-scale tests performed at the Rzeszow
University of Technology (RUT), Poland included, among others, determination of the shear strength along the tyre bale-soil interfaces, because sliding along these interfaces is the controlling mode of the lightweight backfill failure. Three kinds of filling material were tested: the common medium sand, the lightweight expanded clay aggregate (LECA) and the rubber aggregate (shreds). The LECA and rubber filling were considered to further backfill weight reduction as well as - in the latter case - to enhance sustainability of the proposed solution. Based on the backfill strength parameters determined in the experiment, the tyre baled backfill effectiveness was calculated in terms of earth pressure reduction in comparison to the common medium sand backfill. Quantitative analysis for typical retaining wall / abutment was also performed showing considerable savings to be obtained in structural design due to earth pressure reduction . The respective test procedures and results of these tests, as well as the comparative earth pressure analysis, are presented in the paper. The availability of data from such tests and analysis should encourage and accelerate implementation of tyre bales in retaining structure design and construction.

\section{Research significance}

The earth pressure acting on the back of a retaining wall is highly dependent on the properties of the backfill. It is assumed that the lightweight backfill made of tyre bales acts as a self-supporting block, and sliding along the tyre bale-soil interfaces is the controlling mode of failure (Freilich \& Zornberg [9]). The tyre bale interface is defined as the tyre material around the perimeter of the bale, which can be characterised as an irregular and a variable surface. The effect of variable and ridged actual tyre bale surface on the properties of the backfill is a reduction of the tyre bale-soil interface friction angle $(\varphi)$ and a small cohesion (c) as compared to the soil-only parameters. The reduced strength parameters along the tyre bale-soil interface due to a decrease in contact area along the interface result in a weaker plane that exists within the tyre bale backfill. This reduction in tyre bale-soil interface strength is worsened by the presence of water stored in the bales.

To use simple $(\varphi)$ and (c) parameters in a retaining wall equilibrium analysis, these parameters should be experimentally determined depending on the soil used as a filling. Moreover, the stability analyses should utilise the properties of the tyre bales, which must be properly characterised and known for the conditions of the retaining wall. A very limited number of laboratory tests have been 
conducted to determine the interface frictional response of tyre bales for design purposes. Furthermore, their results are highly dependent on the particular method of testing as well as the tyre type used for bale manufacturing. The following laboratory test programme was developed to determine the key strength parameters of a backfill made of tyre bales supplemented with lightweight aggregate needed for the design and construction of retaining walls or bridge abutments with such a backfill. For this purpose, full-scale direct shear tests were conducted to define the interface shear strength between the tyre bales and the filling material. The common medium sand and two lightweight aggregates, LECA and rubber shreds, were used as a filling material. Earth pressure reduction analysis based on the experimental results was performed as well to assess the effectiveness of waste tyre bales used as a backfill for rigid retaining structures.

\section{Materials}

\subsection{Manufacturing of tyre bales}

Tyre bales used in this study comprised whole waste passenger vehicle tyres of R14-R17 type (diameter) compressed into a lightweight block. Each bale and all bales used in the experiment contained only one type and size of tyres. The waste tyres used for bale production had no significant failures, that is, exposed reinforcing steel, halves, quarters or shreds. Tyres were cleaned from dirt, vegetation and organic material and were free of contaminants such as oil, grease or fuel. The production of tyre bales was performed according to specification PAS 108 [20], which addresses the production, handling, storage, transport and placement of standardised tyre bales. Apart from tyre bale dimensions - slightly modified to fit the bailing machine and to facilitate transport - the remaining PAS 108 [20] production requirements, that is, compressing force, density (mass/volume ratio) and the number and tension of steel tie wires, were fulfilled. Tyre bales were fabricated by a lightweight tyre baling machine, designed and manufactured by a bale producer. This baling machine typically compresses approximately $135 \pm 1$ waste tyres into a $2.0-\mathrm{m}^{3}$ bale, and baling results in a 4:1 volume reduction of loose tyres. The consistency of tyre bale production was ensured and controlled by the measurement of steel tie wires' tension. Six 4-mm galvanised steel wires were spaced evenly at $300 \pm 20 \mathrm{~mm}$ along the length of the bale. A typical tyre bale used in this study is shown in Fig. 1.

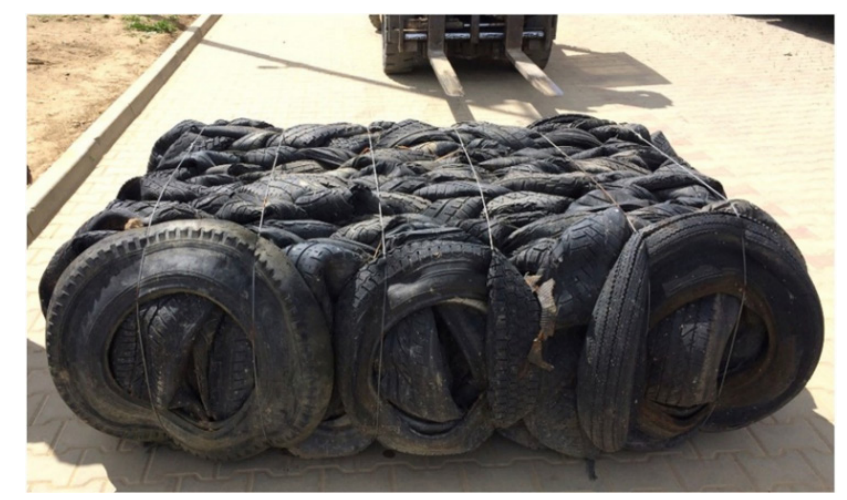

Figure 1: Typical tyre bale used in the current study.

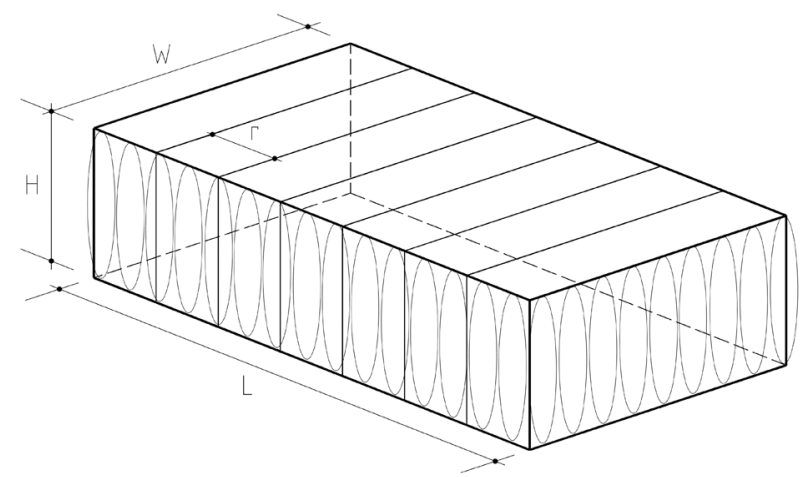

Figure 2: Scheme of a tyre bale with the basic dimensions.

\subsection{Tyre bales' characteristics}

Numerical values for bale's dimensions were determined by taking five measurements each of the length (L), width (B) and height $(\mathrm{H})$ of the bales and calculating the average of each dimension (Fig. 2). The average volume (V) was determined by taking average measurements of the length, width and height of the bales and multiplying them together. To determine the weight (G) of the bales, they were lifted by a load cell system and values were recorded. The unit weight $\left(\mathrm{y}_{\mathrm{AvG}}\right)$ of the tyre bales was determined by the average volume measured. The average dimensions and volume of the bales, their weights and the dry unit weights calculated using the average volume are provided in Table 1.

\subsection{Filling materials}

Three filling materials were applied in this study to supplement tyre-filling direct shear interface test: medium sand, lightweight aggregate (LECA - expanded clay aggregate) and rubber aggregate (waste tyre shreds). 
Table 1: Basic dimensions and weights of tyre bales.

\begin{tabular}{|c|c|c|c|c|c|c|c|c|}
\hline Bale no. & Number of tyres & $\begin{array}{l}\text { Length } \\
\mathrm{L}\end{array}$ & $\begin{array}{l}\text { Width } \\
\text { B }\end{array}$ & $\begin{array}{l}\text { Hight } \\
\text { H }\end{array}$ & $\begin{array}{l}\text { Area } \\
\text { A }\end{array}$ & Volume V & $\begin{array}{l}\text { Weight } \\
\text { G }\end{array}$ & $\begin{array}{l}\text { Unit weight } \\
\text { YAVG }\end{array}$ \\
\hline & & (m) & & & $\left(m^{2}\right)$ & $\left(m^{3}\right)$ & (kg) & $\left(\mathrm{kg} / \mathrm{m}^{3}\right)$ \\
\hline$P-1$ & 135 & 2.070 & 1.310 & 0.747 & 2.712 & 2.026 & 1038 & 512.43 \\
\hline P-2 & 135 & 2.040 & 1.317 & 0.757 & 2.689 & 2.034 & 1022 & 502.50 \\
\hline P-3 & 135 & 2.050 & 1.310 & 0.740 & 2.686 & 1.987 & 1012 & 509.24 \\
\hline P-4 & 135 & 2.040 & 1.323 & 0.737 & 2.699 & 1.989 & 1034 & 519.83 \\
\hline P-5 & 135 & 2.070 & 1.317 & 0.750 & 2.726 & 2.045 & 1049 & 513.05 \\
\hline P-6 & 135 & 2.060 & 1.295 & 0.750 & 2.668 & 2.001 & 1032 & 515.80 \\
\hline Avg. & 135 & 2.055 & 1.312 & 0.747 & 2.697 & 2.014 & 1031 & 512.14 \\
\hline
\end{tabular}

Table 2: Basic material characteristics of the filling materials.

\begin{tabular}{|c|c|c|c|c|c|c|}
\hline \multirow[t]{2}{*}{ Filling material } & Granulation & Weight density & Moisture & Friction angle & Cohesion & \multirow[t]{2}{*}{ State } \\
\hline & $(\mathrm{mm})$ & $\left(\mathrm{kN} / \mathrm{m}^{3}\right)$ & (\%) & $\left({ }^{\circ}\right)$ & $(\mathrm{kPa})$ & \\
\hline Medium sand & $0.25-1.00$ & $18.5 \pm 0.5$ & $12.6-12.8$ & 35.2 & 0 & $\begin{array}{l}\text { Loose / medium } \\
\text { concentrated }\end{array}$ \\
\hline LECA aggregate & $8-20$ & 3.2 & $18.7-22.2$ & 35.3 & 0 & Loose \\
\hline Rubber aggregate & $4-20$ & 4.2 & $9.8-11.0$ & $20.5^{\star}$ & $10.5^{*}$ & Loose \\
\hline
\end{tabular}

*Own tests for high normal stresses

Basic material characteristics of the filling materials used in this study were determined according to the procedures of the domestic Polish standard PN-B-04481 [22], while the direct shear test was conducted with the AB-2a direct shear apparatus according to the standard PKN-CEN [21]. The basic material characteristics determined in these tests are provided in Table 2.

The shear strength envelopes for rubber aggregate are somewhat non-linear and the friction angle is greater at lower confining pressures. A bilinear strength (1) envelope was defined by Humphrey and Manion [13] and Bernal et al. [3] as follows:

$$
\tau=\left\{\begin{array}{l}
\sigma \times \tan \varphi_{1} \rightarrow 0 \leq \sigma \leq 70 \mathrm{kPa} \\
\sigma \times \tan \varphi_{2}+c_{2} \rightarrow 70 \mathrm{kPa} \leq \sigma
\end{array}\right.
$$

where: $\tau$ - shear strength; $\sigma$ - normal stress; $\varphi_{1}, \varphi_{2}-$ friction angle of the material and $c_{2}$ - cohesion of the material.

In authors' own laboratory tests, the mechanical parameters of rubber aggregate were determined for normal stresses above $70 \mathrm{kPa}$. Typically, in the low normal stress range, the angle of internal friction of the rubber aggregate oscillates at about $35^{\circ}$ with no cohesion (Humphrey \& Manion [13], Bernal et al. [3]).

\section{Method}

A full-scale direct shear testing procedure was carried out to determine the interface strength between bales and filling material. This test is similar to that of a soil direct shear test according to the standard PKN-CEN [21] in which the material is forced to fail horizontally along a defined shear plane. The test procedure involved stacking two bales and applying a normal and horizontal (shear) load to the top (sliding) bale while holding the bottom one stationary (Fig. 3). The stationary bale was held in a self-supporting wooden box with dimensions $2.4 \times 1.8 \times 1.0 \mathrm{~m}$ filled with the respective material. A filling material interlayer was placed and compacted on top of the stationary bale to represent the tyre bale-filling material interface and to determine the interface strength. The sliding bale was placed on the interlayer and displaced horizontally with a hydraulic actuator, which was statically mounted on a reaction column. The horizontal (shear) load was applied at a distance of about $0.38 \mathrm{~m}$ (one-half the height of the bale) from the bottom of the sliding bale. An L-shaped, 20-mm-thick steel plate was placed on the sliding bale; the vertical part of the plate distributed the load applied by the actuator on the loaded face of the sliding bale. 


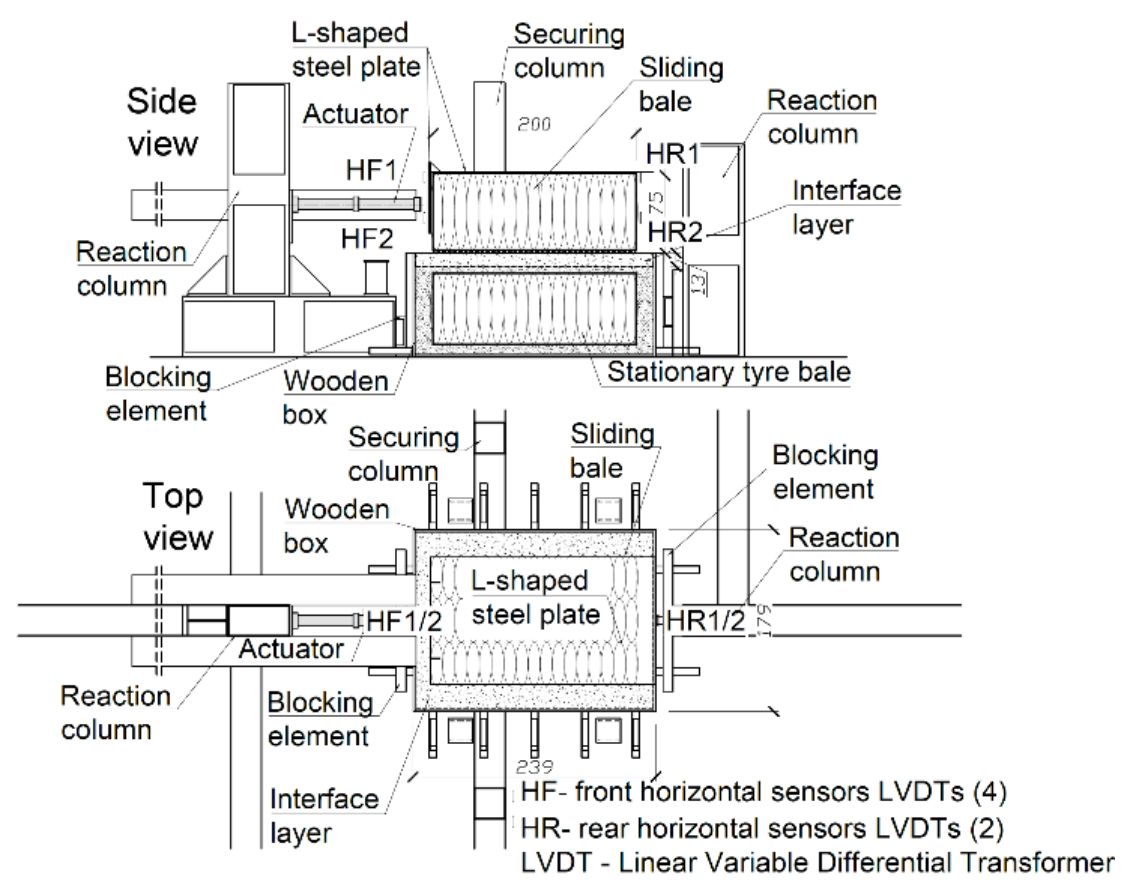

Figure 3: Tyre bale-filling material interface test set-up (without additional normal loading).

The thickness of the interlayer was chosen as about $150 \mathrm{~mm}$ to simulate the typical tyre bale-soil structure composition (Winter et al. [26], Simm et al. [24], Zornberg \& LaRocque [31]) and to ensure that failure occurred along the interface and not within the filling material. Compaction of the interlayer in the box was accomplished with the Wacker Neuson BS-600 rammer with a foot size of $280 \times 336 \mathrm{~mm}$ and a total mass of $66 \mathrm{~kg}$. To simulate wet conditions within a real backfill for a retaining structure, the tyre bale interface and the filling material interlayer were wetted after placement, with water applied by a sprinkler.

Three sliding tyre bales (specimens), P-1, P-2 and P3, were applied in the test, while bale P- 6 used as the bottom bale was held stationary in the box. The normal load (V) was applied gradually by placing additional weight on the sliding bale. The following stages of normal loading were applied subsequently on the sliding bale:

- stage I - the dead weight of the sliding bale and the steel plate $\left(\mathrm{V}_{\mathrm{I}}=22.2 \mathrm{kN}\right)$;

- stage II - the additional weight of a concrete road slab placed on a steel plate $\left(\mathrm{V}_{\mathrm{II}}=28.4 \mathrm{kN}\right)$;

- stage III - the additional weight of a concrete road slab and a tyre bale placed on a steel plate $\left(\mathrm{V}_{\mathrm{III}}=38.4\right.$ $\mathrm{kN})$ and

- stage IV - the additional weight of two concrete road slabs placed on the steel plate $\left(\mathrm{V}_{\mathrm{IV}}=44.0 \mathrm{kN}\right)$.
The failure load is typically determined using two different methods: the bilinear method and the maximum compression method. For the bilinear method, the load displacement curves are approximated as bilinear curves to determine the peak shear load (Freilich \& Zornberg [9]). Failure is defined as the intersection between the two lines that can be approximated for each bilinear portion of the curve. However, La Rocque [14] defined failure as the slipping load at the relevant bale compression. The latter method was used in this study for each stage as follows.

The horizontal load (H) was applied with a speed of $4 \mathrm{~mm} / \mathrm{min}$ until slippage occurred, that is, substantial horizontal displacement of the sliding bale was observed with a noticeable decrease of the horizontal load or the horizontal displacement exceeded $8 \%-10 \%$ of the bale length, that is $160-200 \mathrm{~mm}$. After a slippage had been observed, the horizontal loading was stopped and the actuator piston's displacement was maintained for about 5 min until the load stabilised. This stabilised value of the horizontal load was further considered as the failure shear load. Subsequently, the specimen was unloaded with a speed of $10 \mathrm{~mm} / \mathrm{min}$. Finally, the normal load was removed and changed according to the test programme and the next stage of testing was started. The failure shear load depends on the loading speed. In a real retaining structure, the shear initiating speed is very small within 


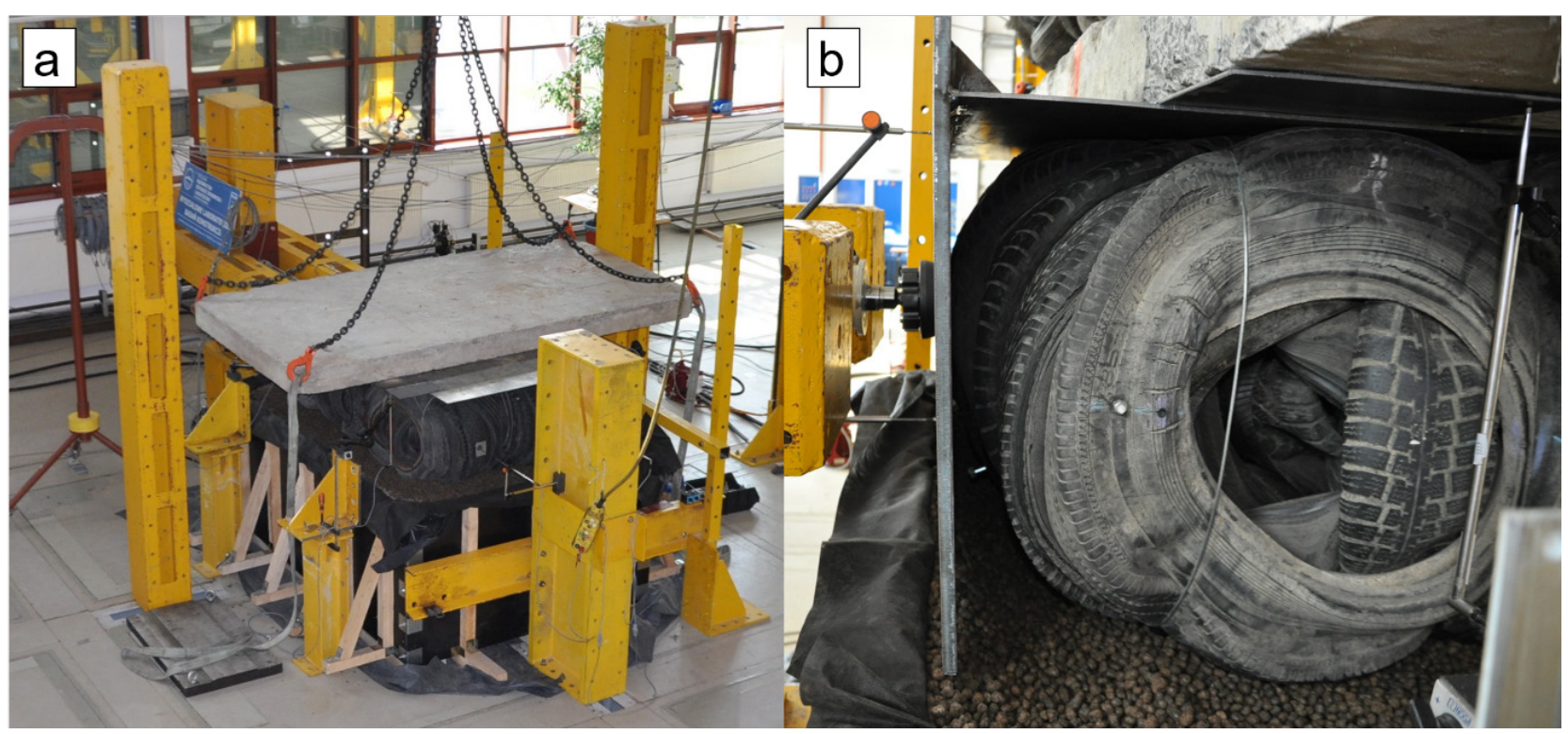

Figure 4: (a) View of the test stand, (b) close-up on LVDTs sensors.
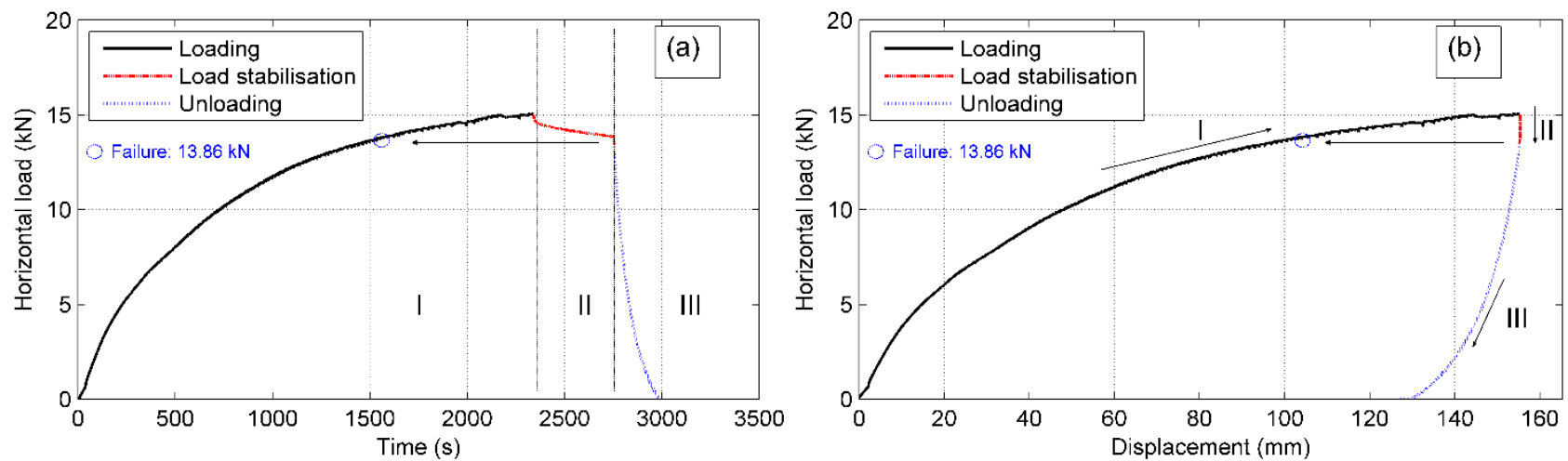

Figure 5: Exemplary curves for P-2 specimen in stage IV of tyre-medium sand shear test: (a) load-time curve, (b) load-displacement curve.

the range of $0.001-0.1 \mathrm{~mm} / \mathrm{min}$. Therefore, the horizontal shear load measured at load stabilisation can be assumed as the minimum failure load which induced slippage. Thus, the real behaviour of a tyre bale built in an actual retaining structure is simulated.

Each specimen was tested three times. Eight LVDT transducers were placed at the front (two sensors), rear (two sensors) and sides (four sensors) of the sliding bale to measure the horizontal and vertical displacements (Fig. 4). The load cell combined with the actuator was used to measure the horizontal load applied to the sliding bale. Load and displacement data were recorded automatically during testing at $0.5 \mathrm{~Hz}$ frequency using the HBM Spider data acquisition system.

\section{Results}

For each experiment (i.e. for each of three specimens, in every normal load stage and for the three filling materials), the load $(\mathrm{H})$-time $(\mathrm{t})$ and the load $(\mathrm{H})$-displacement $(\delta)$ curves were plotted to evaluate the development of shear resistance along the tyre-filling interface as well as to determine the failure load along the interface ( 72 plots in total). In the latter case, the average front displacement of two records (HR1 and HR2) was taken into consideration. The exemplary $\mathrm{H}(\mathrm{t})$ and $\mathrm{H}(\delta)$ curves for the specimen $\mathrm{P}-2$ in the tyre-medium sand shear test under normal load in stage IV (maximum normal load $\mathrm{V}_{\mathrm{IV}}=44.0 \mathrm{kN}$ ) are shown in Fig. 5. The subsequent phases (I, II and III) of the specimen's behaviour under load are marked with colour and the failure load, determined according to the above- 

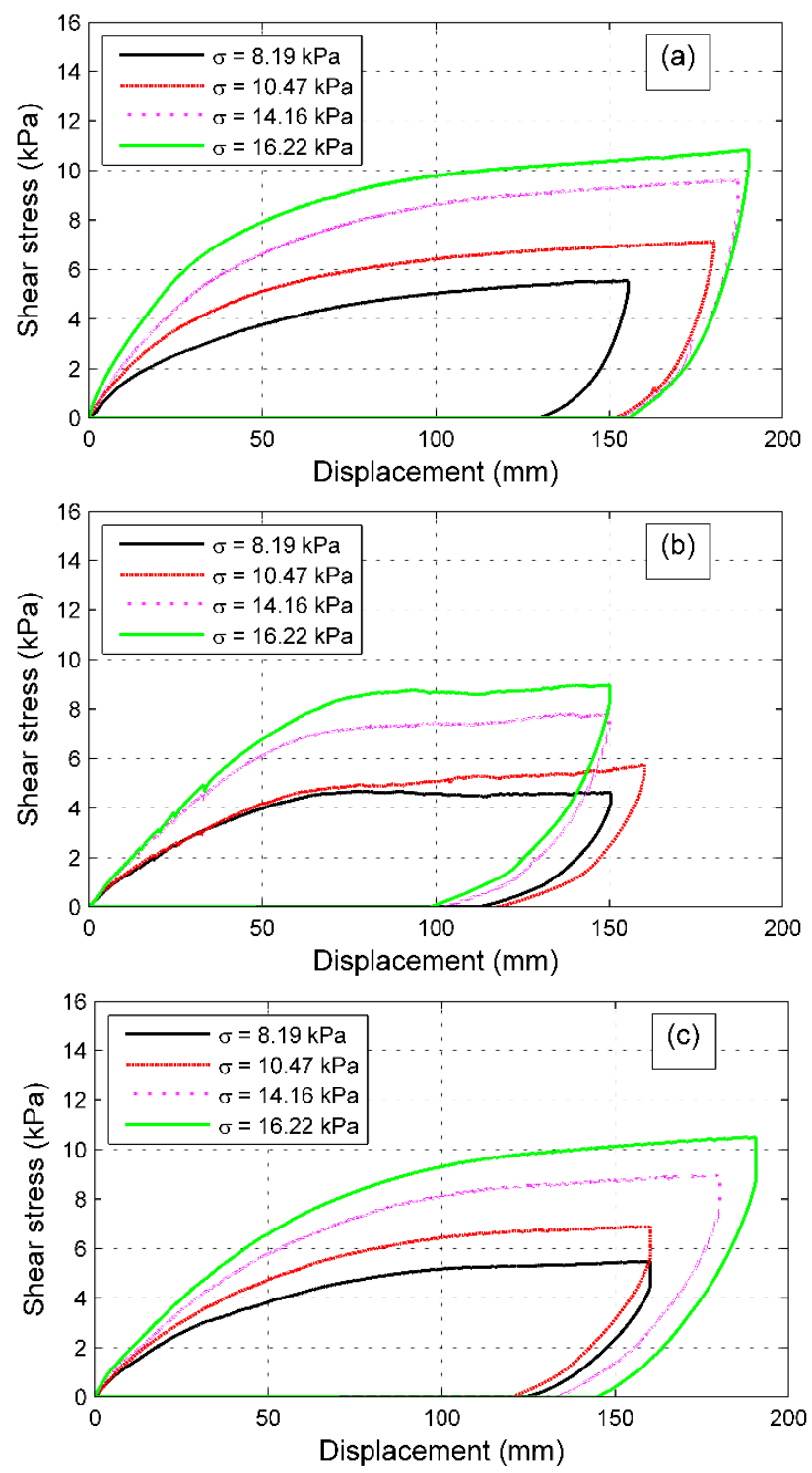

Figure 6: Shear stress-displacement curves for P-2 specimen in subsequent normal load stages: (a) medium sand test, (b) LECA aggregate test, (c) rubber aggregate test.

mentioned procedure (see relevant arrows), is given as well in the figure.

The shear $(\tau)$ and normal $(\sigma)$ stress along the tyre bale interface were defined as the applied load divided by the average area of the tyre bale (Tables 3-5). Typical interface shear stress $(\tau)$ versus horizontal displacement ( $\delta$ ) curves for the exemplary P-2 specimen in all load stages are shown in Fig. 6. Regardless of the applied normal (vertical) stresses, the shear test results obtained in this study showed a similar trend for all filling materials. The curves for medium sand and rubber aggregate are similar qualitatively and quantitively; however, the LECA aggregate test showed a different behaviour. For sand and rubber, no clear failure slippage was observed; in these
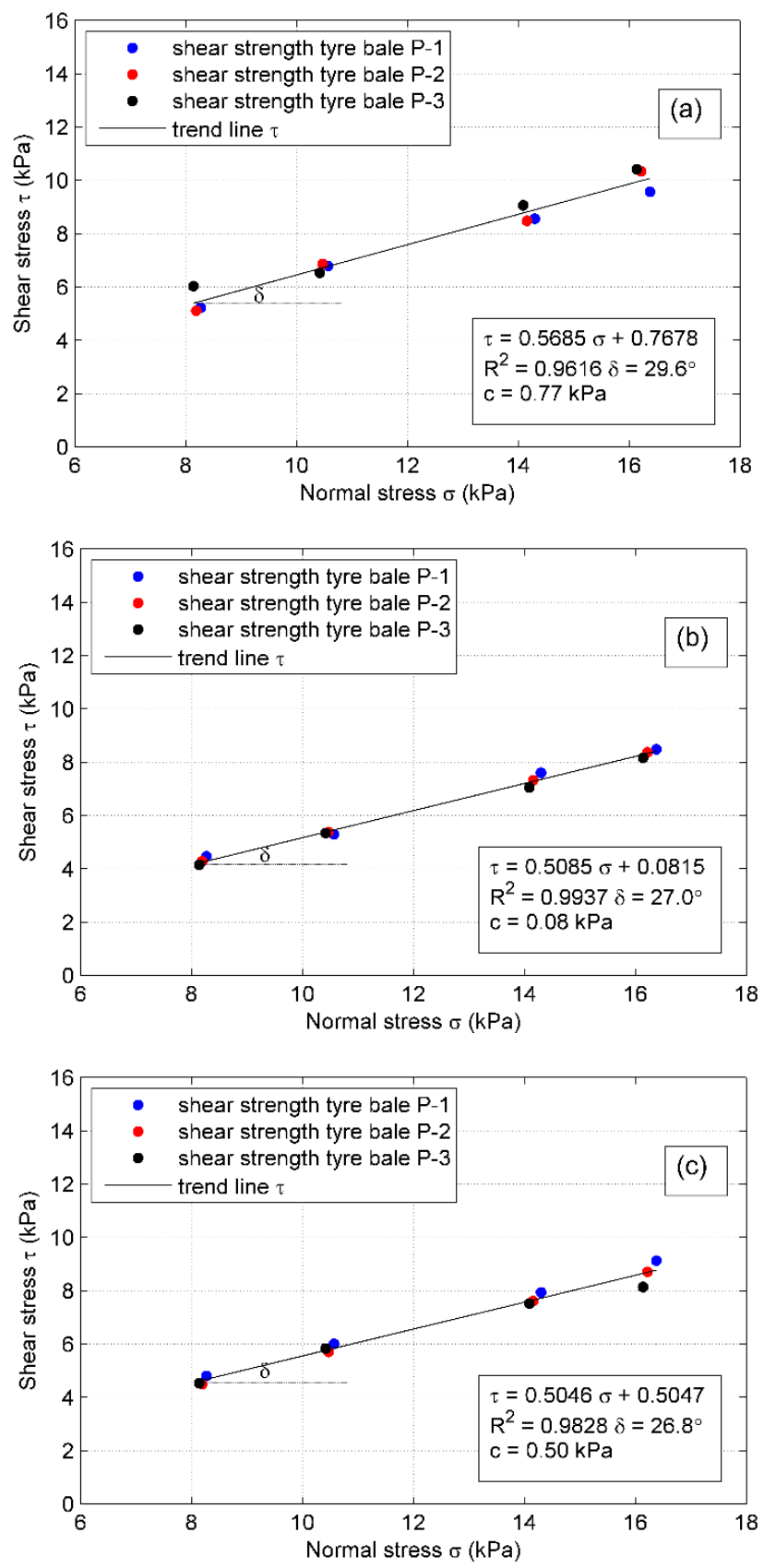

Figure 7: Shear strength envelopes: (a) tyre-medium sand interface, (b) tyre-LECA interface, (c) tyre-rubber aggregate interface.

cases, the failure load was determined when the horizontal displacement exceeded $8 \%-10 \%$ of the bale length. In the case of LECA, substantial horizontal displacement of the sliding bale was observed with a noticeable decrease of the horizontal load.

The highest failure load in subsequent load stages was obtained for medium sand, but for both remaining filling materials, the respective failure loads were very similar (Tables 3-5). However, the shear tests 
Table 3: Shear and normal stresses along the tyre bale-medium sand interface.

\begin{tabular}{|c|c|c|c|c|c|c|c|}
\hline \multirow[t]{2}{*}{ Bale no. } & \multirow{2}{*}{$\begin{array}{l}\text { Area A } \\
\left(m^{2}\right)\end{array}$} & \multirow{2}{*}{$\begin{array}{l}\text { Normal load V } \\
(\mathrm{kN})\end{array}$} & \multirow{2}{*}{$\begin{array}{l}\text { Failure load } \mathrm{H}_{\mathrm{f}} \\
(\mathrm{kN})\end{array}$} & \multirow{2}{*}{$\begin{array}{l}\text { Normal stress } \sigma \\
(\mathrm{kPa})\end{array}$} & \multirow{2}{*}{$\begin{array}{l}\text { Shear stress } \tau \\
(\mathrm{kPa})\end{array}$} & \multirow{2}{*}{$\begin{array}{l}\text { Shear stress } \tau_{\text {cal }} \\
(\mathrm{kPa})\end{array}$} & \multirow{2}{*}{$\begin{array}{l}\text { Error estimation } \\
\text { (\%) }\end{array}$} \\
\hline & & & & & & & \\
\hline \multirow[t]{4}{*}{ P-1 } & 2.686 & 22.2 & 14.01 & 8.27 & 5.22 & 5.47 & 4.58 \\
\hline & & 28.4 & 18.24 & 10.57 & 6.79 & 6.78 & 0.18 \\
\hline & & 38.4 & 23.00 & 14.30 & 8.56 & 8.90 & 3.74 \\
\hline & & 44.0 & 25.71 & 16.38 & 9.57 & 10.08 & 5.05 \\
\hline \multirow[t]{4}{*}{ P-2 } & 2.712 & 22.2 & 13.86 & 8.19 & 5.11 & 5.42 & 5.73 \\
\hline & & 28.4 & 18.61 & 10.47 & 6.86 & 6.72 & 2.10 \\
\hline & & 38.4 & 23.00 & 14.16 & 8.48 & 8.82 & 3.82 \\
\hline & & 44.0 & 28.03 & 16.22 & 10.34 & 9.99 & 3.45 \\
\hline \multirow[t]{4}{*}{ P-3 } & 2.726 & 22.2 & 16.45 & 8.14 & 6.03 & 5.40 & 11.80 \\
\hline & & 28.4 & 17.80 & 10.42 & 6.53 & 6.69 & 2.40 \\
\hline & & 38.4 & 24.70 & 14.09 & 9.06 & 8.78 & 3.25 \\
\hline & & 44.0 & 28.41 & 16.14 & 10.42 & 9.94 & 4.81 \\
\hline
\end{tabular}

Table 4: Shear and normal stresses along the tyre bale-LECA interface.

\begin{tabular}{|c|c|c|c|c|c|c|c|}
\hline \multirow[t]{2}{*}{ Bale no. } & Area A & Normal load V & Failure load $\mathrm{H}_{\mathrm{f}}$ & Normal stress $\sigma$ & Shear stress $\tau$ & Shear stress $\tau_{\text {cal }}$ & Error estimation \\
\hline & $\left(m^{2}\right)$ & $(\mathrm{kN})$ & $(\mathrm{kN})$ & $(\mathrm{kPa})$ & $(\mathrm{kPa})$ & $(\mathrm{kPa})$ & (\%) \\
\hline \multirow[t]{4}{*}{$\mathrm{P}-1$} & 2.686 & 22.2 & 12.00 & 8.27 & 4.47 & 4.28 & 4.28 \\
\hline & & 28.4 & 14.22 & 10.57 & 5.29 & 5.46 & 3.00 \\
\hline & & 38.4 & 20.41 & 14.30 & 7.60 & 7.35 & 3.37 \\
\hline & & 44.0 & 22.79 & 16.38 & 8.48 & 8.41 & 0.87 \\
\hline \multirow[t]{4}{*}{ P-2 } & 2.712 & 22.2 & 11.62 & 8.19 & 4.28 & 4.24 & 0.96 \\
\hline & & 28.4 & 14.59 & 10.47 & 5.38 & 5.41 & 0.49 \\
\hline & & 38.4 & 19.86 & 14.16 & 7.32 & 7.28 & 0.57 \\
\hline & & 44.0 & 22.69 & 16.22 & 8.37 & 8.33 & 0.42 \\
\hline \multirow[t]{4}{*}{ P-3 } & 2.726 & 22.2 & 11.30 & 8.14 & 4.15 & 4.22 & 1.83 \\
\hline & & 28.4 & 14.56 & 10.42 & 5.34 & 5.38 & 0.71 \\
\hline & & 38.4 & 19.23 & 14.09 & 7.05 & 7.24 & 2.63 \\
\hline & & 44.0 & 22.25 & 16.14 & 8.16 & 8.29 & 1.53 \\
\hline
\end{tabular}

revealed a significant difference between the horizontal displacement at failure: in the case of medium sand and rubber aggregate, it exceeded $8 \%-10 \%$ of the bale length; meanwhile, the respective value for LECA was almost twice lower, that is, $3 \%-4 \%$ only. The medium sand and rubber aggregate filling seem to be more 'ductile' than LECA aggregate; so, the retaining structure with tyre bales supplemented with sand or rubber fillings is safer in terms of respective limit state (sliding resistance).
The failure load values observed in the shear tests were used to define the shear strength envelope, which corresponds to the failure points of 12 tests conducted for each filling material. A linear trend line was used to represent a failure envelope passing through the points. The shear strength envelopes are shown in Fig. 7 as a function of the applied normal stress. To derive the shear strength of a tyre-filling material interface, the MohrCoulomb failure criterion was used (2): 
Table 5: Shear and normal stresses along the tyre bale-rubber aggregate interface.

\begin{tabular}{|c|c|c|c|c|c|c|c|}
\hline \multirow[t]{2}{*}{ Bale no. } & \multirow{2}{*}{$\begin{array}{l}\text { Area A } \\
\left(m^{2}\right)\end{array}$} & \multirow{2}{*}{$\begin{array}{l}\text { Normal load V } \\
(\mathrm{kN})\end{array}$} & \multirow{2}{*}{$\begin{array}{l}\text { Failure load } \mathrm{H}_{\mathrm{f}} \\
(\mathrm{kN})\end{array}$} & \multirow{2}{*}{$\begin{array}{l}\text { Normal stress } \sigma \\
(\mathrm{kPa})\end{array}$} & \multirow{2}{*}{$\begin{array}{l}\text { Shear stress } \mathrm{\tau} \\
(\mathrm{kPa})\end{array}$} & \multirow{2}{*}{$\begin{array}{l}\text { Shear stress } \tau_{\text {cal }} \\
(\mathrm{kPa})\end{array}$} & \multirow{2}{*}{$\begin{array}{l}\text { Error estimation } \\
(\%)\end{array}$} \\
\hline & & & & & & & \\
\hline \multirow[t]{4}{*}{ P-1 } & 2.686 & 22.2 & 12.88 & 8.27 & 4.80 & 4.68 & 2.57 \\
\hline & & 28.4 & 16.15 & 10.57 & 6.01 & 5.84 & 2.96 \\
\hline & & 38.4 & 21.32 & 14.30 & 7.94 & 7.72 & 2.83 \\
\hline & & 44.0 & 24.51 & 16.38 & 9.13 & 8.77 & 4.04 \\
\hline \multirow[t]{4}{*}{ P-2 } & 2.712 & 22.2 & 12.18 & 8.19 & 4.49 & 4.64 & 3.11 \\
\hline & & 28.4 & 15.46 & 10.47 & 5.70 & 5.79 & 1.52 \\
\hline & & 38.4 & 20.64 & 14.16 & 7.61 & 7.65 & 0.51 \\
\hline & & 44.0 & 23.62 & 16.22 & 8.71 & 8.69 & 0.21 \\
\hline \multirow[t]{4}{*}{ P-3 } & 2.726 & 22.2 & 12.34 & 8.14 & 4.53 & 4.61 & 1.89 \\
\hline & & 28.4 & 15.88 & 10.42 & 5.83 & 5.76 & 1.10 \\
\hline & & 38.4 & 20.51 & 14.09 & 7.52 & 7.61 & 1.17 \\
\hline & & 44.0 & 22.20 & 16.14 & 8.14 & 8.65 & 5.85 \\
\hline
\end{tabular}

Table 6: Shear strength parameters of tyre-filling interface.

\begin{tabular}{llll}
\hline Filling material & $\begin{array}{l}\text { Friction angle } \\
\Delta\end{array}$ & $\begin{array}{l}\text { Cohesion } \\
\mathbf{c}\end{array}$ & $\begin{array}{l}\text { Determination } \\
\text { coefficient } \mathbf{R}^{2}\end{array}$ \\
\cline { 2 - 3 } $\mathbf{( { } ^ { \circ } )}$ & $(\mathrm{kPa})$ & \\
\hline Medium sand & 29.6 & 0.77 & 0.962 \\
LECA aggregate & 27.0 & 0.08 & 0.994 \\
Rubber aggregate & 26.8 & 0.50 & 0.983 \\
\hline
\end{tabular}

$$
\tau=\sigma \bullet \tan \delta+C
$$

where: $\tau$ - shear strength, $\sigma$ - normal stress, $\delta$ - friction angle of the material (in this case, friction at a tyre-filling interface) and c - cohesion of the material (typically, sandy soils are considered cohesion-less).

The interface shear strength parameters determined from linear regression of the test results are provided in Table 6 . The best curve fitting was obtained for LECA $\left(\mathrm{R}^{2}\right.$ $=0.994)$. However, the coefficients of determination $\mathrm{R}^{2}$ for all three envelopes are acceptable, confirming that the observed test results are very well replicated by the models $\tau(\sigma)$, based on the proportion of total variation of results explained by the envelope. Shear strengths $\tau_{\text {cal }}$ calculated according to the experimental envelopes $\tau(\sigma)$ are given in Tables 3-5, and the errors relative to the experimental results are estimated. Error estimation is within the range of $0.18 \%-11.8 \%$ for medium sand, $0.49 \%-4.28 \%$ for LECA aggregate and $0.21 \%-5.85 \%$ for rubber aggregate. For medium sand, the variability of test results was not more than $12 \%$, but only three results had a deviation of more than 5\%; for both lightweight artificial aggregates, the maximum deviation was also about 5\%. Thus, the variability in the data set was very small.

For the tyre bale-filling material interface, the friction angle $\delta$ was about $16 \%$ and $23.5 \%$ lower for medium sand and LECA or rubber aggregate, respectively. It showed that the frictional response along the tyre bale interface cannot be directly predicted by the direct shear testing of the filling material. The highest shear strength parameters (however, with the lowest coefficient of determination $\mathrm{R}^{2}$ ) were obtained for medium sand. The effect of moisture at the interface was included in the evaluation.

\section{Discussion}

To assess the effectiveness of waste tyre bales used as a backfill for rigid retaining structures, earth pressure reduction analysis based on the experimental results was performed. Estimation of the active earth pressure acting on a rigid retaining wall was made using well-known Coulomb equations assuming that the distribution of active earth pressure exerted against the wall is triangular. The resultant total forces (thrust or lateral active force) generated by various backfills against rigid retaining walls based on the experimental data were calculated assuming three load cases. Fig. 8 shows the active earth pressure distribution on a rigid wall in each load case: a) without a vertical surface load behind the wall; b) with a vertical 
surface load out of a backfill block and c) with a vertical surface load that extends to the backwall. The third case should be considered as an unfavourable action for the verification of bearing capacity, but it is a favourable action with regards to resisting overturning and sliding, and hence should be taken into account in relevant design situations.

The following formulations are proposed for calculating the lateral active forces $\left(E_{S}, E_{T B}\right)$ on a rigid retaining wall depending on the kind of backfill used and the load case:

Case A (without a vertical surface load behind the wall):

- The lateral active force generated by medium sand backfill (common soil used for this purpose):

$$
E_{S}=\frac{1}{2} K_{a} \rho_{s} H^{2}
$$

- The lateral active force generated by tyre baled backfill (with relevant interlayers):

$$
E_{T B}=\frac{1}{2} K_{a} \rho_{s} H^{2}-H b \rho_{b} \tan \delta
$$

Case B (with vertical surface load q out of a backfill block):

- The lateral active force generated by medium sand backfill:

$$
E_{S}=\frac{1}{2} K_{a} \rho_{s} H^{2}+K_{a} q H_{q}
$$

- The lateral active force generated by tyre baled backfill:

$$
E_{T B}=\frac{1}{2} K_{a} \rho_{s} H^{2}+K_{a} q H_{q}-H b \rho_{b} \tan \delta
$$

Case $C$ (with a vertical surface load that extends to the backwall):

- The lateral active force generated by medium sand backfill:

$$
E_{S}=\frac{1}{2} K_{a} \rho_{S} H^{2}+K_{a} q H
$$

- The lateral active force generated by tyre baled backfill:

$$
E_{T B}=\frac{1}{2} K_{a} \rho_{s} H^{2}+K_{a} q H_{q}+\xi_{1} \xi_{2} K_{a, q} q H-\left(H \rho_{b}+q\right) b \tan \varphi_{\text {exp }}
$$

and

$$
K_{a} q H_{q}+\xi_{1} \xi_{2} K_{a, q} q H \leq K_{a} q H
$$

A
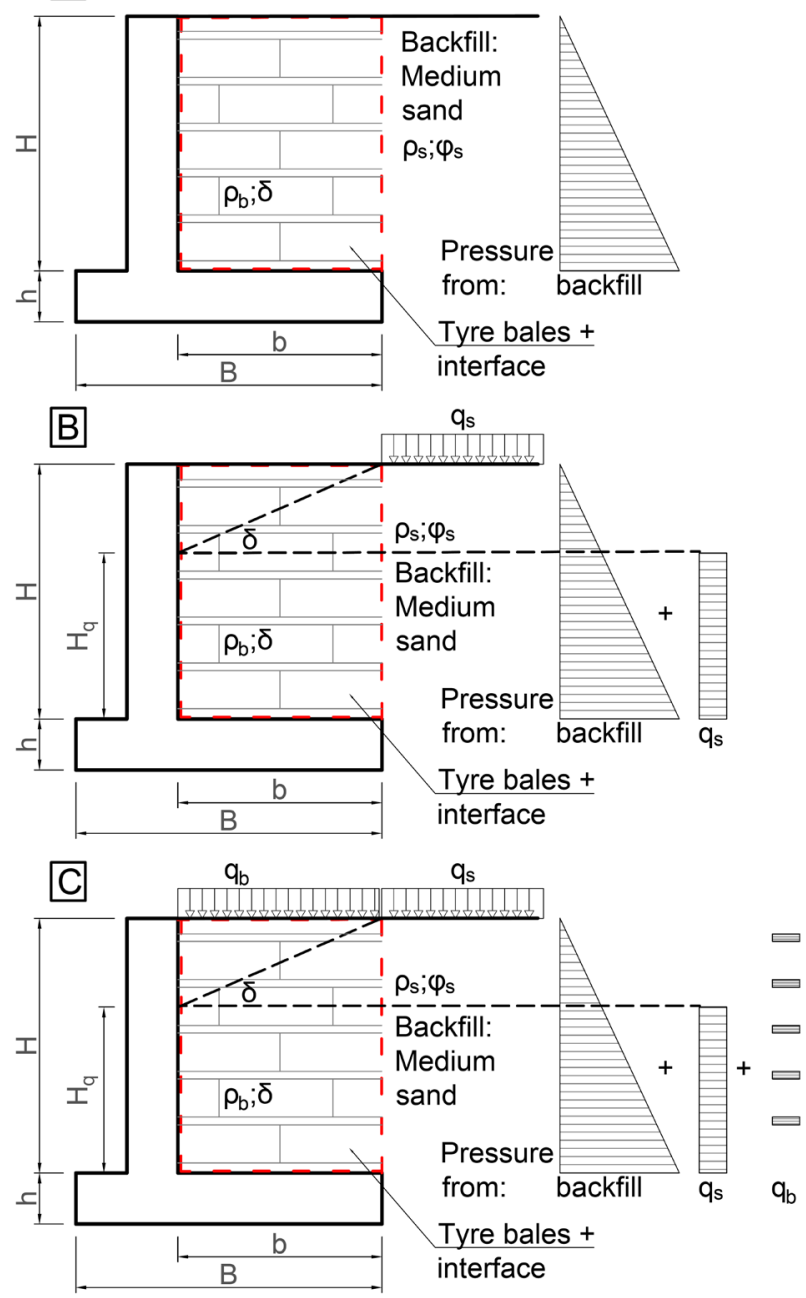

Figure 8: Active earth pressure distribution on a rigid wall in three load cases.

In each case, the earth pressure reduction factor $\left(\lambda_{E}\right)$ was calculated as follows:

$$
\lambda_{E}=1-\frac{E_{T B}}{E_{S}}<100 \%
$$

The following notation was used in the above equations: Backfill material characteristics:

$\varphi_{s}$ - friction angle of medium sand (common soil used for a backfill);

$\delta$ - tyre-soil interface friction angle determined experimentally for medium sand, LECA and rubber aggregate;

$K_{a}=\frac{1-\sin \varphi_{s}}{1+\sin \varphi_{s}}-$ active earth pressure coefficient for medium sand backfill;

$K_{a, q}=\frac{1-\sin \delta}{1+\sin \delta}-$ active earth pressure coefficient for tyre baled backfill with relevant interfaces; 
Table 7: Earth pressure reduction factors $\lambda_{E}$ for a typical bridge abutment $(H=8.0 \mathrm{~m}, b=4.0 \mathrm{~m})$ and standard vertical surface load $(q=25 \mathrm{kPa})$.

\begin{tabular}{|c|c|c|c|c|c|c|}
\hline \multirow[t]{2}{*}{ Backfill type } & $\rho_{I L}$ & $\rho_{\text {TB }}$ & $\rho_{b}$ & $\varphi_{b}$ & $E_{S} / E_{T B}$ & $\lambda_{E}$ \\
\hline & $\overline{k N} / \mathrm{m}^{3}$ & $\mathrm{kN} / \mathrm{m}^{3}$ & $\mathrm{kN} / \mathrm{m}^{3}$ & 0 & $\mathrm{kN} / \mathrm{m}$ & $\%$ \\
\hline \multicolumn{7}{|l|}{ Case A } \\
\hline Medium sand & 19.00 & 0.00 & 19.00 & 35.0 & 164.8 & 0.0 \\
\hline Tyre-sand & 19.00 & 5.40 & 7.67 & 29.6 & 25.4 & 84.6 \\
\hline Tyre-LECA & 5.25 & 5.40 & 5.38 & 27.0 & 77.1 & 53.2 \\
\hline Tyre-rubber & 5.40 & 5.40 & 5.40 & 26.8 & 77.5 & 53.0 \\
\hline \multicolumn{7}{|l|}{ Case B } \\
\hline Medium sand & 19.00 & 0.00 & 19.00 & 35.0 & 200.0 & 0.0 \\
\hline Tyre-sand & 19.00 & 5.40 & 7.67 & 29.6 & 64.2 & 67.9 \\
\hline Tyre-LECA & 5.25 & 5.40 & 5.38 & 27.0 & 117.5 & 41.2 \\
\hline Tyre-rubber & 5.40 & 5.40 & 5.40 & 26.8 & 118.0 & 41.0 \\
\hline \multicolumn{7}{|l|}{ Case C } \\
\hline Medium sand & 19.00 & 0.00 & 19.00 & 35.0 & 219.0 & 0.0 \\
\hline Tyre-sand & 19.00 & 5.40 & 7.67 & 29.6 & 17.1 & 92.2 \\
\hline Tyre-LECA & 5.25 & 5.40 & 5.38 & 27.0 & 76.8 & 64.9 \\
\hline Tyre-rubber & 5.40 & 5.40 & 5.40 & 26.8 & 77.7 & 64.5 \\
\hline
\end{tabular}

The standard vertical surface load $q=25 \mathrm{kPa}$ according to PN-EN 1997-1 [23] was applied in this assessment.

$\rho_{s}$ - weight density of medium sand;

$\rho_{b}$ - average weight density of tyre baled backfill:

$\rho_{b}=\frac{h_{L L} \rho_{L L}+h_{T B} \rho_{T B}}{h_{I L}+h_{T B}}$

$\rho_{I L}$ - weight density of the filling material (interlayer);

$\rho_{T B}$ - weight density of the tyre bales;

$h_{I L}$ - thickness of the interlayer in the backfill;

$h_{T B}-$ thickness of the tyre bale.

Retaining wall geometry (Fig. 8):

$H$ - height of the wall above footing (a stem, backfill height);

$h$ - depth of the footing;

$H_{q}$ - height of the wall with pressure from uniform vertical surface load 'b' away from the wall;

$H_{q}=H-b \times \tan \delta$

$B$ - width of the wall's footing;

$b$ - width of the wall's footing under backfill (a heel);

$\xi_{1}, \xi_{2}$ - the effective wall height factors:

$\xi_{1}=\frac{h_{I L}}{h_{I L}+h_{T B}}$

$\xi_{2}=\frac{b \tan \left(\frac{\pi}{4}+\frac{\delta}{2}\right)}{H}$

Surface loading (Fig. 8):

$q$ - vertical surface load; $q_{s}$ - the part of vertical surface load out of a backfill block; $q_{b}$ - the part of vertical surface load above a backfill block.

Assuming the values of friction angles $\varphi_{s}$ and $\delta$ as well as weight density of the filling materials according to the test results (Tables 2 and 6, respectively) and taking into account the actual thicknesses of tyre bales $\left(h_{T B}=0.75 \mathrm{~m}\right)$ and interlayers $\left(h_{I L}=0.15 \mathrm{~m}\right)$, the reduction efficiency factors $\lambda_{E}$ can be calculated depending on the load case and the wall dimensions using Equation (10). To assess quantitively the earth pressure reduction to be achieved by using tyre baled backfills, in Table 7, the $\lambda_{E}$ factors are provided for a typical bridge abutment ( $H=8.0 \mathrm{~m}, b=4.0 \mathrm{~m})$.

As can be seen in Table 7, the worst case concerning earth pressure reduction is load case $B$, that is, with vertical surface load out of a backfill block. The estimated total reduction of earth pressure owing to the tyre baled backfill application amounts to about $70 \%$ for medium sand filling and about $40 \%$ for artificial fillings, that is, LECA and rubber shreds. However, in the latter case, about $70 \%$ reduction of backfill (block) weight can be achieved as compared to the common medium sand backfill, which is crucial for the foundation of the retaining structure in soft-soil conditions. Regardless of the kind of tyre baled 
Table 8: Earth pressure reduction factor $\lambda_{E}$ in dependence on the wall's geometry.

\begin{tabular}{|c|c|c|c|c|c|c|c|c|}
\hline \multirow{2}{*}{\multicolumn{2}{|c|}{$\begin{array}{l}\text { Earth pressure reduction } \\
\text { factor } \lambda \mathrm{E}\end{array}$}} & \multicolumn{7}{|l|}{$H(m)$} \\
\hline & & 4 & 5 & 6 & 7 & 8 & 9 & 10 \\
\hline \multirow[t]{6}{*}{$b(m)$} & 1 & 26.0 & 22.3 & 19.6 & 17.5 & 15.8 & 14.5 & 13.3 \\
\hline & 2 & 56.2 & 47.1 & 40.8 & 36.1 & 32.4 & 29.5 & 27.0 \\
\hline & 3 & 91.7 & 74.6 & 63.6 & 55.7 & 49.7 & 45.0 & 41.2 \\
\hline & 4 & 100.0 & 100.0 & 88.3 & 76.6 & 67.9 & 61.2 & 55.7 \\
\hline & 5 & 100.0 & 100.0 & 100.0 & 98.7 & 86.9 & 77.9 & 70.7 \\
\hline & 6 & 100.0 & 100.0 & 100.0 & 100.0 & 100.0 & 95.3 & 86.3 \\
\hline
\end{tabular}

backfill, the geometry of the retaining structure $(\mathrm{H}, \mathrm{b})$ has a considerable effect on the active earth pressure magnitude. This influence is shown in Table 8 for the best tyre-sand backfill, the worst loading case (B) and the standard vertical surface load $q=25 \mathrm{kPa}$. This estimation revealed that for retaining structures with a height up to $6 \mathrm{~m}$, total reduction of the active earth pressure can be obtained, depending on the width of the wall's footing under backfill (a heel). To facilitate the assessment of active earth pressure reduction using the proposed procedure, a 3-D plot is provided in Fig. 9, in which the $\lambda_{E}$ factor can be estimated depending on the retaining wall's geometry.

\section{Conclusions}

Waste tyre bales offer a useful construction mean for earth pressure reduction of rigid retaining structures. To assess the reduction level, the shear strength properties of the tyre bales and the baled structures must be properly determined by experiment. Laboratory full-scale tests were carried out to determine the shear strength parameters along the tyre bale-soil interfaces in the lightweight backfill. Waste tyre bales of approximate dimensions $2.05 \times 1.30 \times 0.75 \mathrm{~m}$, a mass of around 1030 $\mathrm{kg}$, an average volume of around $2.0 \mathrm{~m}^{3}$ and unit weight of approximately $0.515 \mathrm{mg} / \mathrm{m}^{3}$ were used in this study, supplemented in a backfill with three filling materials: common medium sand, LECA and rubber aggregate. Based on the backfill strength parameters, the analytical procedure was applied to estimate the comparative earth pressure reduction in each case.

The conclusions from each part of the current study apply to the design and construction of the tyre baled retaining structures. Brief outlines of the conclusions

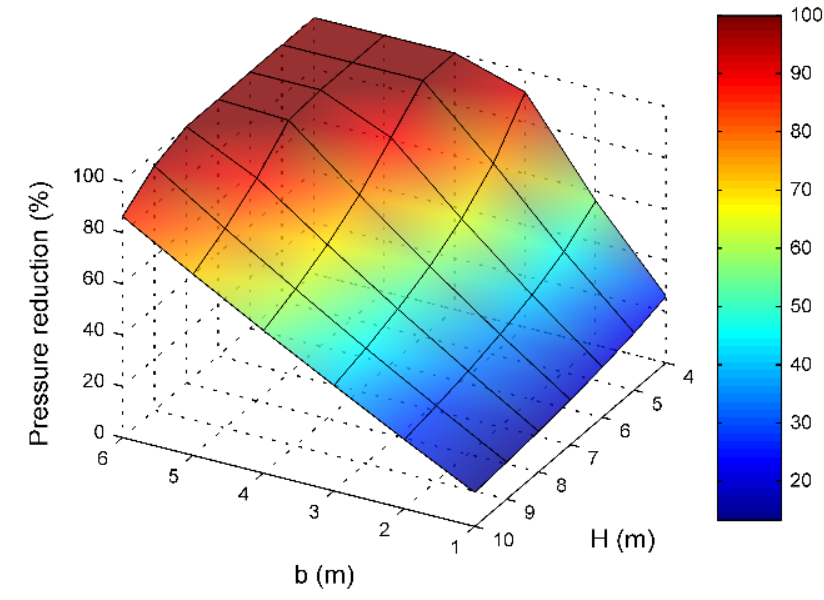

Figure 9: Earth pressure reduction factor $\lambda_{\mathrm{E}}$ in dependence on the wall's geometry.

stated throughout the paper are presented below, providing the resultant values.

- The experimental tests revealed a reduction of the tyre bale-soil interface friction angle ( $\delta$ ) and a small cohesion (c) as compared to the soil-only parameters. The friction angles $\delta=30^{\circ}$ and $\delta=27^{\circ}$ were experimentally determined for a tyre baled backfill with medium sand and LECA or rubber aggregate interlayers (filling), respectively. It means a $16 \%$ and $23.5 \%$ reduction as compared to the respective filling only angles; for comparison, usually, the angle of soil friction $\delta$ against a concrete wall is assumed to be $33 \%$ lower than the angle $\varphi$ of internal friction of the material.

- The results from the tyre-filling interface testing can be combined and modelled with a linear failure envelope, indicating small variability of test results not more than $12 \%$. Very good curve fitting was obtained for all lightweight backfills, confirming that 
the observed test results are very well replicated by the proposed $\tau(\sigma)$ models.

- Estimation of the active earth pressure acting on a rigid retaining structure made using experimental shear strength parameters and Coulomb theory revealed about $70 \%$ pressure reduction for the tyre bale-sand backfill and about $40 \%$ pressure reduction for the tyre bale-LECA / rubber backfill.

- As the earth pressure reduction depends on the wall's geometry, the analysis revealed that the total pressure reduction could be obtained in case of the wall's height up to $6 \mathrm{~m}$ and the footing heel width above $4 \mathrm{~m}$. A 3-D plot is provided to facilitate the effective retaining structure design.

In addition to the research described above, the authors conducted a series of experimental and numerical tests on waste tyre bales used as a backfill for integral bridges. The experiment was prepared and conducted utilising a special full-scale trial built to simulate actual bridge abutment conditions. The experiment revealed that the pressure (both active and at-rest) on the abutment backwall was significantly lower in the case of the tyre baled backfill when compared to a common medium sand backfill (Duda \& Siwowski [5]). Based on the current and aforementioned testing results, the first Polish application of abutment backfill made of the tyre bales in a road bridge was designed and executed (Duda \& Siwowski [6]).

Finally, it should be emphasised that waste tyre bales may be a significant source of harmful chemicals and heavy metals that may contaminate soils and groundwater if leached at high concentrations (Gualtieri et al. [10], Hennebert et al. [11], Liu et al. [15], Banasiak et al. [2]). Unfortunately, this could, in turn, have significant environmental implications and limit the use of tyre bale technology in many projects if not properly addressed. To assess these environmental implications, comprehensive research was carried out in the frame of this project to determine whether tyre bales cause pollution of groundwater and soil, as well as what level of leaching of undesirable substances takes place (Duda et al. [7]).

Data Availability Statement: The data that support the findings of this study are available from the corresponding author, $\mathrm{AD}$, upon reasonable request.

Acknowledgements: This work was supported by the European Regional Development Fund within the R\&D project called 'ReUse-Innovative Recycling Materials, Enhancing the Sustainability of Bridge Facilities' (Innotech programme, grant no. K3 / IN3 / 38 / 228116 / NCBiR / 15) and the project industry partners: Promost Consulting, Rzeszow, Remost Debica and Geotech, Rzeszow, Poland.

\section{References}

[1] Ahn, I-S., Cheng, L., Fox, P., Wright, J., Patenaude, S., Fujii, B. (2015). Material Properties of Large-Size Tire Derived Aggregate for Civil Engineering Applications. Journal of Materials in Civil Engineering, Volume 27 Issue 9, https://doi.org/10.1061/ (ASCE)MT.1943-5533.0001225

[2] Banasiak, L.J., Chiaro, G., Palermo, A., Granello, G. (2021). Environmental implications of the recycling of end-of-life tires in seismic-isolation foundation systems. Advances in Sustainable Construction and Resource Management, Lecture Notes in Civil Engineering, 144, 43-52, https://doi. org/10.1007/978-981-16-0077-7_5

[3] Bernal, A., Lovell, C. W., Salgado, R. (1996). Laboratory Study on the Use of Tire Shreds and Rubber-Sand in Backfilled and Reinforced Soil Applications. Publication FHWA/IN/JHRP-96/12. In Joint Highway Research Project, Indiana Department of Transportation and Purdue University.

[4] Bo, M. W., Yarde, A. (2006). Use of waste tyre bales to construct a flood embankment. Proceedings of the Institution of Civil Engineers - Waste and Resource Management, 159(2). https:// doi.org/10.1680/warm.2006.159.2.57

[5] Duda, A., Siwowski, T. (2020a). Pressure evaluation of bridge abutment backfill made of waste tyre bales and shreds: Experimental and numerical study. Transportation Geotechnics, 24. https://doi.org/10.1016/j.trgeo.2020.100366

[6] Duda, A., Siwowski, T. (2020b). Experimental Investigation and First Application of Lightweight Abutment Backfill Made of Used Tyre Bales. In Lecture Notes in Civil Engineering (Vol. 47). https://doi.org/10.1007/978-3-030-27011-7_9

[7] Duda, A., Kida, M., Ziembowicz, S., Koszelnik, P. (2020). Application of material from used car tyres in geotechnics-an environmental impact analysis. PeerJ 8:e9546 https://doi. org/10.7717/peerj.9546

[8] Esmaeili, M., Zakeri, J. A., Ebrahimi, H., \& Khadem Sameni, M. (2016). Experimental study on dynamic properties of railway ballast mixed with tire derived aggregate by modal shaker test. Advances in Mechanical Engineering, Vol. 8(5), 1-13, https:// doi.org/10.1177/1687814016640245

[9] Freilich, B., Zornberg, J. (2009). Mechanical Properties of Tire Bales for Highway Applications. Report No. FHWA/TX-10/05517-1. Center for Transportation Research. The University of Texas at Austin.

[10]Gualtieri, M., Andrioletti, M., Vismara, C., Milani, M., Camatini, M. (2005). Toxicity of tire debris leachates. Environment International 31(5), 723-730, https://doi.org/10.1016/j. envint.2005.02.001

[11] Hennebert, P., Lambert, S., Fouillen, F., Charrasse, B. (2014). Assessing the environmental impact of shredded tires as embankment fill material. Canadian Geotechnical Journal, 51(5), 469-478,

[12] Humphrey, D. N., Blumenthal, M. (2010). The Use of TireDerived Aggregate in Road Construction Applications. Green Streets and Highways Conference 2010, November 
14-17, 2010, Denver, Colorado, United States, https://doi. org/10.1061/41148(389)25

[13] Humphrey, D. N., Manion, W. P. (1992). Properties of tire chips for lightweight fill. Geotechnical Special Publication, 2(30), 1344-1355.

[14] LaRocque, C. J. (2005). Mechanical Properties of Tire Bales. Department of Civil, Architectural and Environmental Engineering, The University of Texas at Austin.

[15] Liu, L., Cai, G., Zhang, J., Liu, X., Liu, K. (2020). Evaluation of engineering properties and environmental effect of recycled waste tire-sand/soil in geotechnical engineering: a compressive review. Renewable and Sustainable Energy Reviews 126:109831, https://doi.org/10.1016/j. rser.2020.109831

[16] Meles, D., Bayat, A., Hussien Shafiee, M., Nassiri, S., \& Gul, M. (2014). Investigation of tire derived aggregate as a fill material for highway embankment. International Journal of Geotechnical Engineering, 8(2), 182-190. https://doi.org/10.1179/19397879 $13 Y .0000000015$

[17] Mills, B., McGinn, J. (2010). Design, Construction, and Performance of a Highway Embankment Failure Repaired with Tire-Derived Aggregate. Transportation Research Record, 2170(1), 90-99. https://doi.org/10.3141/2170-11

[18] Mittal, R. K., Gill, G. (2018). Sustainable application of waste tire chips and geogrid for improving load carrying capacity of granular soils. Journal of Cleaner Production, 200, 542-551. https://doi.org/https://doi.org/10.1016/j.jclepro.2018.07.287

[19] Ni, P., Qin, X., Yi, Y. (2018). Use of tire-derived aggregate for seismic mitigation of buried pipelines under strike-slip faults. Soil Dynamics and Earthquake Engineering, Volume 115, pp. 495-506, https://doi.org/10.1016/j.soildyn.2018.09.018

[20] PAS (Publicly Available Specification). 2007. Specification for production of tyre bales for use in construction. PAS 108. London: PAS.

[21] PKN-CEN (Polish Committee for Standardization - European Committee for Standardization). 2009. Geotechnical investigation and testing. Laboratory testing of soil. Part 10: Direct shear tests. PKN-CEN ISO/TS 17892-10:2009. Warsaw: PKN-CEN.

[22] PN (Polish Standards). 1988. Building soils -- Tests of soil samples. PN-B-04481. Warsaw: PN.

[23] PN-EN (Polish Standards). 2008. Eurocode 7: Geotechnical design - Part 1: General rules. PN-EN 1997-1. Warsaw: PN-EN.

[24] Simm, J. D., Winter, M. G., Waite, S. (2008). Design and specification of tyre bales in construction. Proceedings of Institution of Civil Engineers: Waste and Resource Management, 161(2). https://doi.org/10.1680/ warm.2008.161.2.67

[25] Sol-Sánchez, M., Moreno-Navarro, F., Tauste-Martínez, R., Saiz, L., Rubio-Gámez, M.C. (2020). Recycling Tire-Derived Aggregate as elastic particles under railway sleepers: Impact on track lateral resistance and durability. Journal of Cleaner Production, Volume 277, 20, https://doi.org/10.1016/j.jclepro.2020.123322

[26] Winter, M. G., J. M. Reid, P. I. J. Griffiths. (2005). Tyre Bales in Construction: Case Studies. TRL Ltd, Crowthorne, 2005, Report PPR 045.

[27] Winter, M. G., Williammee, R., Prikryl, W. (2009). Application of tyre bales to slope failure repair. Proceedings of the Institution of Civil Engineers: Engineering Sustainability, 162(3).
[28] Xiao, M., Bowen, J., Graham, M., Larralde, J. (2012). Comparison of Seismic Responses of Geosynthetically Reinforced Walls with Tire-Derived Aggregates and Granular Backfills. Journal of Materials in Civil Engineering, Volume 24 Issue 11,

https://doi.org/10.1061/(ASCE)MT.1943-5533.0000514

[29] Zornberg, G. J., B. R. Christopher, C. J. LaRocque. (2004). Applications of Tire Bales in Transportation Projects. In Recycled Materials in Geotechnics (pp. 42-60). https://doi. org/doi:10.1061/40756(149)3

https://doi.org/10.1680/ensu.2009.162.3.145

[30] Zornberg, J. G., Christopher, B. R., Oosterbaan, M. D. (2005). Tire bales in highway applications: feasibility and properties evaluation. http://ftp.dot.state.tx.us/pub/txdot-info/ gsd/pdf/tire_bales.pdf https://academic.microsoft.com/ paper/2135272966

[31] Zornberg, J., LaRocque, C. J. (2006). Engineering Properties of Tire Bales for Soil Repairs and Embankment Construction. Department of Civil, Architectural and Environmental Engineering, The University of Texas at Austin. 